\title{
Kinetics of Free Radical Polymerization of N-Substituted Amides and Their Structural Implications
}

\author{
Anca Aldea, ${ }^{1}$ Ana-Maria Albu, ${ }^{2}$ Alina Nicolescu, ${ }^{3,4}$ and Victorita Tecuceanu ${ }^{3}$ \\ ${ }^{1}$ Department of General Chemistry, University Politehnica Bucharest, 1-7 Gheorghe Polizu Sector 1, 011061 Bucharest, Romania \\ ${ }^{2}$ Department of Bioresources and Polymer Science, University Politehnica Bucharest, 1-7 Gheorghe Polizu Sector 1, \\ 011061 Bucharest, Romania \\ ${ }^{3}$ Centre for Organic Chemistry Costin D. Nenitescu, Romanian Academy, 202B Splaiul Independentei, CP 35-108, \\ 060023 Bucharest, Romania \\ ${ }^{4}$ Institute of Macromolecular Chemistry "Petru Poni” Iasi, 41A Aleea Grigore Ghica Voda, 700487 Iasi, Romania
}

Correspondence should be addressed to Ana-Maria Albu; anamarialbu@yahoo.com

Received 28 January 2016; Revised 30 May 2016; Accepted 23 June 2016

Academic Editor: Peter Chang

Copyright (C) 2016 Anca Aldea et al. This is an open access article distributed under the Creative Commons Attribution License, which permits unrestricted use, distribution, and reproduction in any medium, provided the original work is properly cited.

Two $\mathrm{N}$-substituted amides ( $\mathrm{N}$-acryloyl morpholine and $\mathrm{N}$-methyl- $\mathrm{N}$-vinylacetamide) were polymerized in different solvents using radical initiator. The tacticity of obtained polymers was determined by $400 \mathrm{MHz}{ }^{1} \mathrm{H}-\mathrm{NMR}$ and ${ }^{13} \mathrm{C}-\mathrm{NMR}$. At a given temperature, the syndiotacticity increased with increasing the solvent polarity. This solvent effect may be related to the hydrogen bonding interaction among solvent, monomer, and/or growing species. A peculiar aspect regards the steric hindrance at the nitrogen atom.

\section{Introduction}

In the area of smart materials, a peculiar attention is paid to the stimuli-responsive material architectures based on water-soluble polymers. They have been widely investigated for their applications in medicine, biotechnology, food, or cosmetics. An actual orientation of materials science field is designing and developing the stimuli-responsive nanostructured materials [1].

The approaches of modern polymer chemistry accept the challenges of increasing the precision and the complexity of these material systems to drive their properties beyond those of established responsive polymers [2-8]. The possibility to alter polymer properties through external stimuli could be successfully exploited to obtain "smart" block copolymers, polymer aggregates, polymer gels, or polymer surface brushes. Indeed, these methods can provide strong advantages in obtaining active polymer materials.

A special attention was paid to the $\mathrm{N}$-substituted amides (co)polymers such $\mathrm{N}$-isopropyl acrylamide (NIPAM), Nmethyl methacrylamide (NMMAM), $\mathrm{N}$-acryloyl morpholine (NAM), and so forth $[9,10]$.

Recognized for its reactivity, NAM copolymerizes with many different monomers and the synthesized materials, like all the materials derived from disubstituted acrylamides, are characterized by solubility in a wide range of solvents, from aqueous to organic ones. Due to its ability to give high molecular weight polymers with a virtual lack of toxicity, NAM is used in the last years to synthesize crosslinked networks for gel phase, synthesis of peptides, or drug delivery applications, protecting liposomes from blood clearance or increasing the lifetime of enzymes both in vitro and in vivo [11-13]. Alongside NAM, materials based on $\mathrm{N}$-methyl-N-vinylacetamide (NMNVA) can be an alternative for water-soluble multifunctional materials for immobilization of single stranded DNA probes. Nowadays, the NMNVA copolymers are used for charge density modelling in relation to the molecular weight; the most important means for applications are polymer liquid crystals, DNA architecture, multilayer/expanded films, and so forth $[9,14,15]$. A specific property of the materials derived from structural isomers of $\mathrm{N}$-alkyl acrylamide class is their lower critical solution temperature (LCST) [16]. The most poignant example for how structural configuration of these materials affected the LCST is poly(N-isopropyl acrylamide) (PNIPAM): a gradual decrease is recorded with increasing the isotacticity, and, for an isotactic $(\mathrm{mm})$ triad, the insolubility in water appears to be over $72 \%$, although the atactic (mr) PNIPAM is one of the representative water-soluble polymers 
<smiles>C=CC(=O)N1CCOCC1</smiles>

NAM

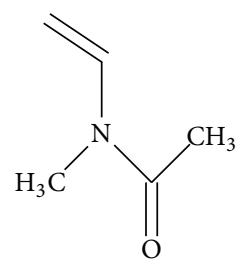

NMNVA
FIGURE 1: Monomers structures: N-acryloyl-morpholine (NAM) and N-methyl-N-vinylacetamide (NMNVA).

[17]. Therefore, the stereoregulation of the structure has a strong influence on the solubility of the product.

Among the many techniques for structural control of polymers, a particular attention is focused on the tacticity control in the radical synthesis of polymers. This method has many advantages, but an important one is the possibility of leading this mechanism at industrial level. Under chiral circumstances, this approach has been applied even to radical polymerization known to be difficult to setup for stereocontrol, due to the flat orbital at the end of the growing polymer chain [18]. The best method for controlling the micromolecular organization, in this case, attained for several types of monomers [19-21], is using the solvent and temperature effects. Another influence in this technical direction is given by the monomer concentration, whose effect was revealed in the radical stereosynthesis of methacrylate and acrylic polymers $[22,23]$.

Recently, the study of parameters, which affects the microtacticity, discloses that the hydrogen bonding interactions are an important way to control the stereospecificity in the radical polymerization of $\mathrm{N}$-alkyl acrylamides and substituted vinyl ethers [16].

According to these research directions, the goal of our paper is to discuss the influence of the solvent on the structure of NAM and, respectively, NMNVA (Figure 1) polymers, without neglecting the kinetics of the process on which there is not much information in the literature.

\section{Experimental}

2.1. Materials. NAM and NMNVA were purchased from Merck and purified by distillation under reduced pressure. The initiator used was 2, $2^{\prime}$-azobisisobutyronitrile (AIBN) and benzoyl peroxide (BPO) purchased from Aldrich and purified by recrystallization procedure. Solvents used were as follows: tetrahydrofuran (THF) and 1,4-dioxane from Aldrich, toluene and diethyl ether (as precipitation agent) from Chimopar SA, anisole from Merck-Schuchardt, diphenyl ether (DPE) from Fluka-AG, and methanol from SC PAM Corporation SRL. All the solvents were purified by usual methods.

2.2. Synthesis. For this study, two synthesis methods were used to investigate the materials from different points of view.

The first one was the dilatometric technique to determine the kinetics of the polymerization. For this case, the monomer concentration in the feed was 2 mole/L; Initiator used was benzoyl peroxide and the initial concentration $[\mathrm{BPO}]_{0}$ was $5 \times 10^{-3} \mathrm{~mole} / \mathrm{L}$. The solvents used in this method were tetrahydrofuran (THF), 1,4-dioxane (D), and toluene (T). The working temperatures were 65 and $75^{\circ} \mathrm{C}$, respectively. The polymers have been separated by diethyl ether precipitation, washed, and dried at $40^{\circ} \mathrm{C}$ under vacuum for minimum of 12 hours.

The second procedure was classic radical polymerization: the needed quantities of monomer, solvent, and initiator were placed in standard Pyrex glass tubes. The reaction mixture was flushed with nitrogen for 2 minutes and then soldered and placed in a thermostated silicon oil bath at the working temperature $\left(75^{\circ} \mathrm{C}\right)$. The monomer concentration in the feed was $2 \mathrm{~mole} / \mathrm{L}$; AIBN concentration was $5 \times 10^{-3} \mathrm{~mole} / \mathrm{L}$. The used solvents were as follows: tetrahydrofuran (THF), 1,4dioxane (D), toluene (T), anisole (An), and diphenyl ether (DPE). The polymers (poly(NAM) and poly(NMNVA)) have been isolated by precipitation in diethyl ether, washed several times with nonsolvent, and dried under vacuum at $40^{\circ} \mathrm{C}$ for minimum of 12 hours.

2.3. Characterization. To accomplish the goal of this work and to underline the structural peculiarities for obtained polymers, structure and composition of the samples have been determined by FT-IR, ${ }^{1} \mathrm{H}\left({ }^{13} \mathrm{C}\right) \mathrm{NMR}$ spectroscopy, and elemental analysis, respectively.

${ }^{1} \mathrm{H}-\mathrm{NMR}$ and ${ }^{13} \mathrm{C}$-NMR spectra have been obtained in dimethylsulphoxide with a Bruker Avance DRX 400 Instrument.

For FT-IR spectroscopy, a Brucker VERTEX 70 instrument, equipped with a Harrick MVP2 diamond ATR device apparatus, has been used.

\section{Results and Discussions}

3.1. Kinetics Investigations. The first aspect of our study proposes a preliminary investigation of chemical reactivity of the two monomers, by experimental determination of the initial rate of polymerization in different solvents. We used the dilatometric technique to measure conversions and reaction rates.

An idealized kinetic model for free radical polymerizations expresses the rate of polymerization as

$$
R_{p}=\frac{k_{p}}{\sqrt{k_{t}}}[M]_{0} \sqrt{2 f k_{d}[I]_{0}},
$$

where $k_{d}, k_{p}$, and $k_{t}$ are the initiator decomposition, propagation, and termination rate constants, respectively; $f$ is the initiator efficiency factor (a constant for an initiatormonomer-solvent system); $[M]_{0}$ and $[I]_{0}$ are the initial monomer and initiator concentrations, respectively; a factor of 2 arises from generation of 2 moles of primary radicals from the decomposition of a mole of initiator. $k_{p} /\left(k_{t}\right)^{1 / 2}$ is a characteristic ratio which is a measure of a given monomer's propensity for kinetic growth. In real systems, often free radical polymerizations are far removed from this ideality. 


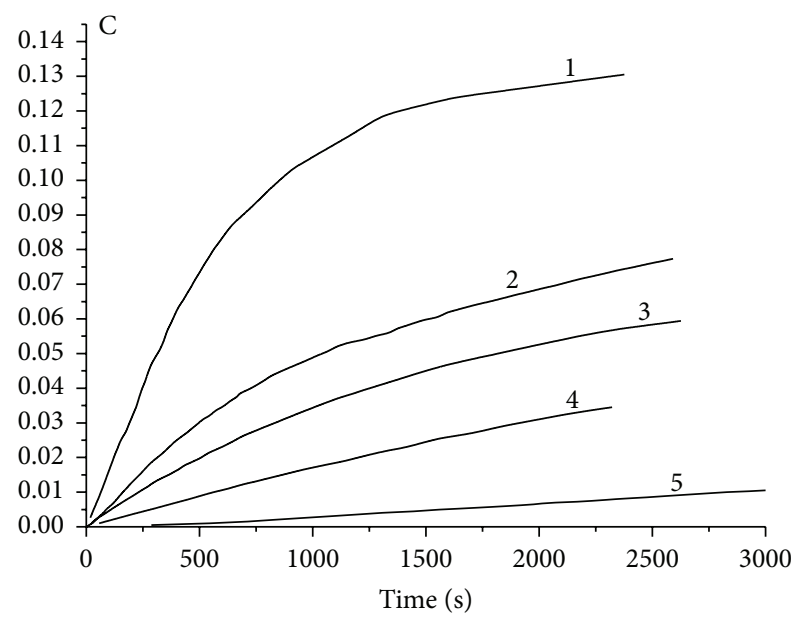

(a)

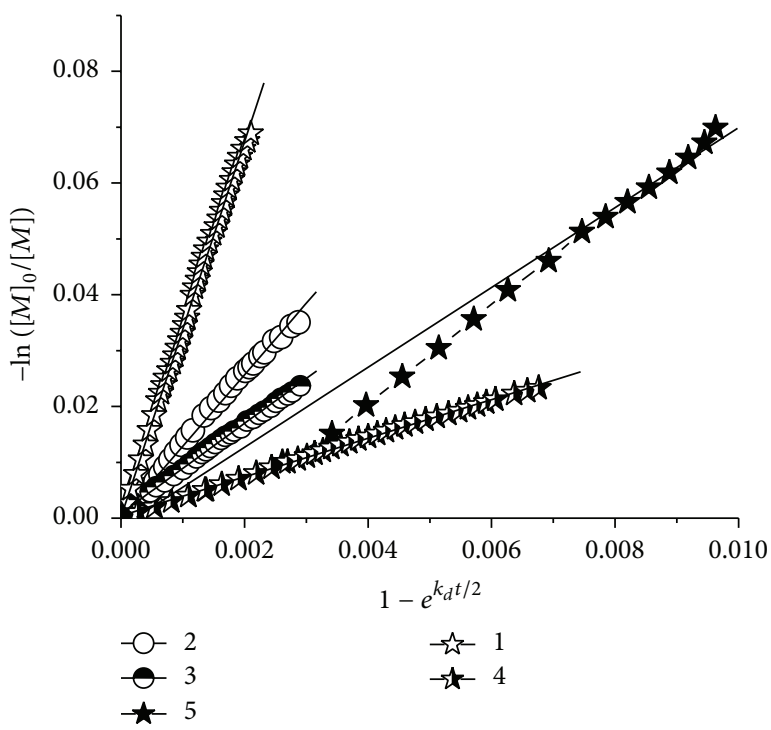

(b)

FIGURE 2: Conversion-time curves based on dilatometric results (a) and data of $\ln [M]_{0} /[M]$ as a function of $1-\left(1-e^{k_{d} t / 2}\right)$ according to (5) (b), where 2-poly(NMNVA) in 1,4-dioxane; 3-poly(NMNVA) in toluene; 5-poly(NAM) in 1,4-dioxane; 1-poly(NAM) in THF; 4-poly(NAM) in toluene.

Chain transfer reactions with $\mathrm{H}$-abstraction occur at the active site of a primary radical or a macroradical, potentially involving any species present in the system: initiator, solvent, monomer, polymer, and so forth. These may prematurely terminate a growing macroradical, limiting the kinetic chain growth.

Taking into account the initial value of the height of the liquid in the capillary and because the polymerization process is accompanied by volume contraction, the polymerization rate can be written as

$$
R_{p}=\alpha \frac{\Delta h[M]_{0}}{\Delta t}
$$

where $\Delta t$ is time lapse from $t=0 ; \Delta h$ is change in the capillary height at $\Delta t$; and $[M]_{0}$ is initial concentration of the monomer (mole/L). Accurate determination of contraction factor $d[M]_{0} / \Delta h$ in mole/mm for a given capillary and the change in capillary height corresponding to full conversion $\left(\Delta h^{\infty}\right)$ enable the expression of monomer conversions in moles $\mathrm{L}^{-1} \mathrm{~s}^{-1}$ and \% conversions, respectively. Therefore, the curves height-time can be converted into conversion-time variation using the following relation:

$$
c_{i}=K_{D} \Delta H_{i},
$$

where $c_{i}, \Delta H_{i}$ is the conversion of respective dilatometric height at current time and $K_{D}$ (Table 1) is contraction factor, a specific constant strictly lied to the pair solvent//monomer//polymer.

The process of evolution in different solvents for both monomers, shown in Figure 2, reveals the absence of the induction period. The polymerization rate is relatively high and influenced by the polarity of reaction medium (Table 1): the global polymerization rate increases by increasing the solvent polarity index. The recorded decreasing of $R_{p}$ for NAM polymerization in dioxane (row 3) can be explained only by particular interaction of (like hydrogen bonding) vinyl group-solvent.

The collected data from these experiments were used to assess $k_{p} /\left(k_{t}\right)^{0.5}$ ratio, based on the following equations:

$$
\begin{aligned}
& R_{p}=-\frac{d[M]}{d t}=k_{p}\left(\frac{f k_{d}[I]}{k_{t}}\right)^{0.5}, \\
& {[I]=[I]_{0} e^{-k_{d} t},}
\end{aligned}
$$

by integration of the following:

$$
-\ln \frac{[M]_{0}}{[M]}=2\left(\frac{k_{p}}{\sqrt{k_{t}}}\right)\left(\frac{2 f[I]_{0}}{k_{d}}\right)^{0.5}\left(1-e^{-k_{d} t / 2}\right)
$$

where $[M]$ is the monomer concentration at experimental time $t, k_{p}, k_{t}, k_{d}$ denoting the absolute propagation, termination, and initiator decomposition rate, and $f$ is the initiator efficiency.

Applying (3) the momentary monomer, concentration was obtained. Based on these data, dependence $\ln [M]_{0} /[M]$ versus $\left(1-e^{k_{d} t / 2}\right)$ was drawn and it is illustrated in Figure 2(b). From the slope of linear plot $\left(k_{d}=1.5 \times 10^{-6} \mathrm{~s}^{-1}\right.$ and $f=$ 0.75 for BPO at $\left.60^{\circ} \mathrm{C}[24]\right), k_{p} /\left(k_{t}\right)^{0.5}$ are given for each homopolymerization experiment (Table 1$)$.

The obtained values are in the same range with those of acrylamide or methacrylamide derivatives (Table 2). $k_{p} /\left(k_{t}\right)^{0.5}$ is relatively high for acrylamide but is a noticeable diminution with the nature of reaction medium and the 

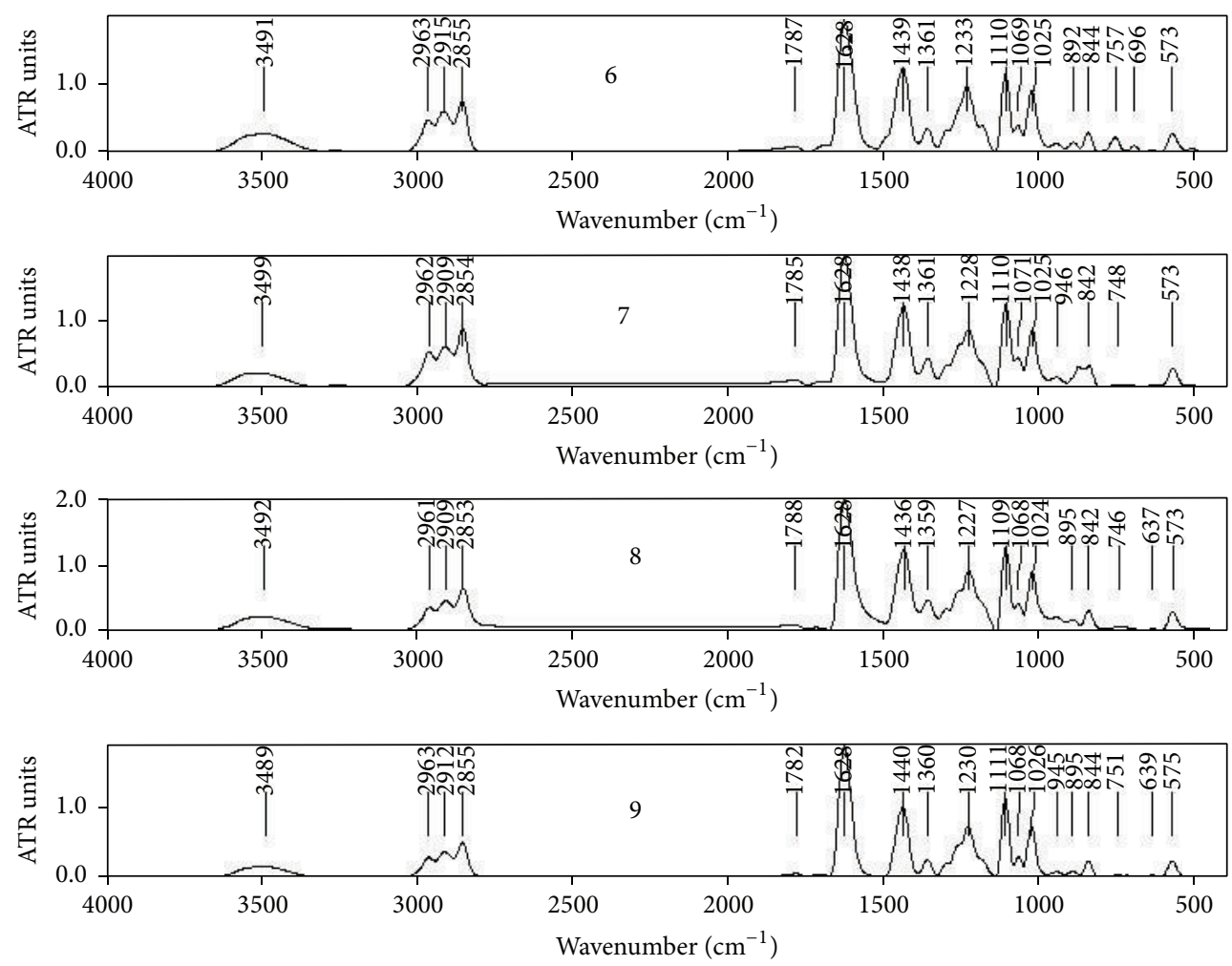

FIGURE 3: FT-IR spectra of poly(NAM) synthesized in different solvents by radical polymerization: 6 in anisole, 7 in 1,4-dioxane, 8 in toluene, and 9 in THF.

TABLE 1: Features of dilatometric measurements for poly(NAM) and for poly(NMNVA).

\begin{tabular}{lcccc}
\hline Code & $10^{2} K_{D}$ & $C_{f}(\%)$ & $R_{p}(\mathrm{~mol} / \mathrm{L} \mathrm{s})$ & $k_{p} / \sqrt{k_{t}}$ \\
\hline $\begin{array}{l}\text { Poly(NMNVA) in } \\
\text { 1,4-dioxane }\end{array}$ & 2.60 & 7.7 & $1.033 \times 10^{-4}$ & 0.233 \\
$\begin{array}{l}\text { Poly(NMNVA) in } \\
\text { toluene }\end{array}$ & 2.20 & 5.9 & $7.100 \times 10^{-5}$ & 0.150 \\
$\begin{array}{l}\text { Poly(NAM) in } \\
\text { 1,4-dioxane }\end{array}$ & 10.00 & 1.1 & $7.000 \times 10^{-6}$ & 0.130 \\
$\begin{array}{l}\text { Poly(NAM) in THF } \\
\text { Poly(NAM) in }\end{array}$ & 5.22 & 13.0 & $3.440 \times 10^{-4}$ & 0.611 \\
toluene & 2.00 & 3.4 & $3.500 \times 10^{-5}$ & 0.064 \\
\hline
\end{tabular}

In all experiments, $[M]_{0}$ is 2 mole $/ \mathrm{L} ;[I]_{0}$ is $5 \times 10^{-3}$ mole $/ \mathrm{L} ; T$ is $60^{\circ} \mathrm{C}$. $K_{D}$ is contraction factor; $C_{f}$ is final conversion; $R_{p}$ is polymerization rate; $k_{p} / \sqrt{k_{t}}$ is the ratio between the propagation and termination constants.

degree of nitrogen substitution. On the contrary, methacrylamide is about the increase of value $k_{p} /\left(k_{t}\right)^{0.5}$ for the $\mathrm{N}$ substituted derivatives. The nature of solvent affects these values [24].

All these behaviours can be attributed to the influence of the side chain as it was reported in the case of alkyl (meth)acrylates: $k_{p} / k_{t}^{0.5}$ value decrease was more likely due to a decreasing of termination constant $\left(k_{p} / k_{t}^{0.5}=0.59\right.$ for lauryl methyl methacrylate instead of 0.04 for methyl methacrylate), as a consequence of increasing the steric hindrance. Such an effect may also appear in the case of NMNVA and NAM homopolymerization related to the medium polarity: this can be provided by the two complexes, monomer-solvent and reactive polymer-solvent, respectively. A maximum value is obtained for NAM in THF. The first consequence of these observations can be retrieving the molar mass value of product (Table 3 ). Indeed, the increasing of the polarity index of medium causes an increasing of the molar weight. Generally, at moderate value of polarity index, NAM seems to be more reactive, perhaps due to the inexistence of a conjugation of the vinyl group with the substituent.

3.2. Physicochemical Characterizations. The polymers obtained through classical radical polymerization have been characterized in terms of chemical structure, molecular weight, and thermal behaviour.

3.2.1. Structural Investigations. The FT-IR analyses (see Figure 3 as an example) mark out the specific absorption of the structural atomic groups [29].

Thereby, analyzing the spectra from Figure 3, the broad absorption at $3491-3500 \mathrm{~cm}^{-1}$ was assigned to complexed ternary amide for both monomers. At $2850-2960 \mathrm{~cm}^{-1}$ (s-m) are recorded the antisymmetrical and symmetrical stretching of $\mathrm{CH}$ and $\mathrm{CH}_{2}$ from the backbone and $\mathrm{CH}_{2}$ and $\mathrm{CH}_{3}$ sidechain groups. The weak band around $1700 \mathrm{~cm}^{-1}$ is assigned to $\mathrm{C}=\mathrm{O}$ stretching (amide $\mathrm{I}$ ) and the intense absorption from $1628 \mathrm{~cm}^{-1}$ to $\mathrm{C}=\mathrm{O}$ stretching (amide II). $\mathrm{CH}_{2}$ scissor vibrations are situated at $1437 \mathrm{~cm}^{-1}$ and the weak wagging and 
TABLE 2: $k_{p} / k_{t}^{0.5}$ values for different acrylamide and methacrylamide.

\begin{tabular}{|c|c|c|c|c|}
\hline \multirow{2}{*}{ Monomer } & \multirow{2}{*}{$\begin{array}{c}k_{p} / k_{t}^{0.5} \\
(\mathrm{~L} / \mathrm{moles})^{0.5}\end{array}$} & \multicolumn{2}{|c|}{ Process parameters } & \multirow{2}{*}{ Reference } \\
\hline & & $T\left({ }^{\circ} \mathrm{C}\right)$ & Solvent & \\
\hline \multirow{4}{*}{ Acrylamide } & 3.50 & 19 & $\mathrm{H}_{2} \mathrm{O}$ & \multirow{4}{*}[24]{} \\
\hline & 1.98 & 25 & $\mathrm{H}_{2} \mathrm{O} / \mathrm{D}=9: 1$ & \\
\hline & 1.82 & 30 & $\mathrm{H}_{2} \mathrm{O} / \mathrm{DMF}=9: 1$ & \\
\hline & 0.22 & 26 & DMSO & \\
\hline Methacrylamide & 0.20 & 25 & $\mathrm{H}_{2} \mathrm{O}$ & {$[25]$} \\
\hline \multirow{2}{*}{ N, N-Dimethyl acrylamide } & 0.46 & 30 & $\mathrm{H}_{2} \mathrm{O}$ & \multirow{2}{*}[26]{} \\
\hline & 1.78 & 50 & $\mathrm{H}_{2} \mathrm{O}$ & \\
\hline $\mathrm{N}$-(2,2-Dimethoxy ethyl)-N-methyl acrylamide & 1.00 & 50 & DMF & {$[27]$} \\
\hline 6-Deoxy-6-methacryloylamido-D-glucopyranose & 1.00 & 50 & $\mathrm{H}_{2} \mathrm{O}$ & {$[28]$} \\
\hline
\end{tabular}

TABLE 3: Dimensional characteristics of poly(NAM) and poly(NMNVA).

(a) Poly(NAM)

\begin{tabular}{lccccc}
\hline Code & IP & $C(\%)$ & $M_{n}(\mathrm{DP})$ & $M_{w}$ & $I_{D}$ \\
\hline 6 (anisole) & 3.8 & 99.0 & $28165(200)$ & $42327(45611)^{1}$ & 1.50 \\
7 (1,4 dioxane) & 4.8 & 90.6 & $12279(87)$ & $58065(48572)^{1}$ & 4.73 \\
8 (toluene) & 2.4 & 71.0 & $31709(225)$ & $126879(148572)^{1}$ & 4.00 \\
9 (THF) & 4.0 & 79.0 & $3633(26)$ & $11349(19350)^{1}$ & 3.12 \\
\hline
\end{tabular}

(b) Poly(NMNVA)

\begin{tabular}{lccccc}
\hline Code & IP & $C(\%)$ & $M_{n}(\mathrm{DP})$ & $M_{w}$ & $I_{D}$ \\
\hline 10 (methanol) & 5.2 & 64.2 & - & $(21947)^{1}$ & - \\
11 (1,4 dioxane) & 4.8 & 75.9 & $5587(56)$ & $23947(24719)^{1}$ & 4.28 \\
12 (THF) & 4.0 & 73.4 & $4387(44)$ & $20894(21452)^{1}$ & 4.76 \\
13 (toluene) & 2.4 & 53.3 & $17729(179)$ & $63748(61650)^{1}$ & 3.40 \\
\multirow{2}{*}{14 (diphenyl ether) 2.2} & $21.1^{2}$ & - & $(19769)^{1}$ & - \\
& & $52.5^{3}$ & - & $(24719)^{1}$ & - \\
\hline
\end{tabular}

${ }^{1}$ In the brackets the estimated value from the elemental analysis.

${ }^{2}$ Liquid phase. ${ }^{3}$ Solid phase.

IP is polarity index; $C$ is conversion; $M_{n}(\mathrm{DP})$ is number average molecular weight degree of polymerization; $M_{w}$ is molecular weight; $I_{D}$ is dispersity index.

twist $\mathrm{CH}_{2}, \mathrm{CH}$, at $1360 \mathrm{~cm}^{-1}$. For NAM are recorded weak signals for transamide III at $1299 \mathrm{~cm}^{-1}$ and intense ones for ester bond at $1026 \mathrm{~cm}^{-1}$.

For both polymers, the absorption from $1110 \mathrm{~cm}^{-1}$ is assigned to the skeleton modes, coupled for NMNVA with $\mathrm{CH}_{3}$ rocking. The median band at $841-843 \mathrm{~cm}^{-1}$ is assigned to $\mathrm{CH}$ situated out of the plane and $\mathrm{CH}_{2}$ wagging and twisting on morpholine ring. At $573 \mathrm{~cm}^{-1}$ can be noticed $\mathrm{C}=\mathrm{O}$ bending out of the plane.

It is know that the solvent polarity induces the tacticity in polymerization products. This is an interesting and important aspect especially because the solvent effect in radical polymerization is neglected except in some systems where the influence of the solvent relates to the transfer process.

The literature underlines that the polarity of solvent may induce the selectivity at conformational level: syndiotactic (rr) configuration increases with increasing the solvent polarity. This is strictly related to the interaction among solvent, monomer, and growing polymer chain [19-23].

In both proposed cases for study, the nitrogen atom from amide group together with the carbonyl group might contribute to the appearance of hydrogen bonding interactions. Although the solvent effect cannot be completely rationalized, it can be assumed that the presence of the hydrogen bonding between monomer and growing chain decreases syndiotactic specificity.

Reproducing same experiment in a large range of solvent, we obtained information regarding the molecular dimension and stereochemical structure (Tables 3 and 4). All experiments developed as a homogeneous process, excepting the DPE for the NMNVA case. Usually, the heterogeneous evolution of a homogeneous system can be due to the existence of a critical molecular dimension, decreasing the compatibility polymer//mixture solvent-unreacted monomer, or to a peculiarly molecular configuration of the monomer units in the chain. In fact, in both cases, the polymerization changes the chain polarity. Particularly, in this case, considering the small size differences between the polymers, the two-phase evolution seems to be a consequence of the configuration of the monomer units in the polymer chains.

The elemental analysis allows a theoretical estimation of the molecular dimensions. The calculated fractions (\%) of AIBN sequence in the polymer are in the accepted limit, under $1 \%$, and we could estimate the dimension of materials. The obtained results (Table 3) are in good accordance with monomer composition and molar mass values obtained by GPC (polystyrene standard):

(i) For NAM, the lowest molecular weight value was obtained for THF that can be construed as activation process by monomer complexation. Consequently, the number of the initial propagation radicals is higher than in other cases. A particular evolution is recorded for anisole solvent: the polydispersity index is low.

(ii) For NMNVA is respected the same tendency reported in the case of NAM: the value of molar weight increases with decreasing the polarity of the solvent 
TABLE 4: Evolution of poly(NMNVA) tacticity.

\begin{tabular}{|c|c|c|c|c|c|c|c|c|c|c|c|}
\hline \multirow{2}{*}{ Solvent } & \multirow{2}{*}{ IP } & \multicolumn{3}{|c|}{$\alpha$} & \multicolumn{3}{|c|}{$\beta$} & \multicolumn{2}{|c|}{$\mathrm{Pr} / \mathrm{m}$} & \multicolumn{2}{|c|}{$\mathrm{Pm} / \mathrm{r}$} \\
\hline & & $\mathrm{rr}$ & $\mathrm{mr}$ & $\mathrm{mm}$ & $\mathrm{rr}$ & $\mathrm{mr}$ & $\mathrm{mm}$ & $\alpha$ & $\beta$ & $\alpha$ & $\beta$ \\
\hline 1,4-Dioxane & 4.8 & 39 & 37 & 24 & 36 & 41 & 23 & 0.322 & 0.363 & 0.435 & 0.471 \\
\hline THF & 4.0 & 31 & 40 & 29 & 36 & 37 & 27 & 0.392 & 0.339 & 0.408 & 0.407 \\
\hline Toluene & 2.4 & 48 & 30 & 22 & 44 & 37 & 19 & 0.238 & 0.296 & 0.405 & 0.493 \\
\hline
\end{tabular}

IP is polarity index; $\alpha$ and $\beta$ are the two regions from NMR spectra used to estimate the tacticity; rr is isotactic fraction; mr is atactic fraction; $\mathrm{mm}$ is syndiotactic fraction; $\mathrm{Pr} / \mathrm{m}$ is the conditional probability; and $\mathrm{Pm} / \mathrm{r}$ is the reverse probability from Bernoullian statistics.

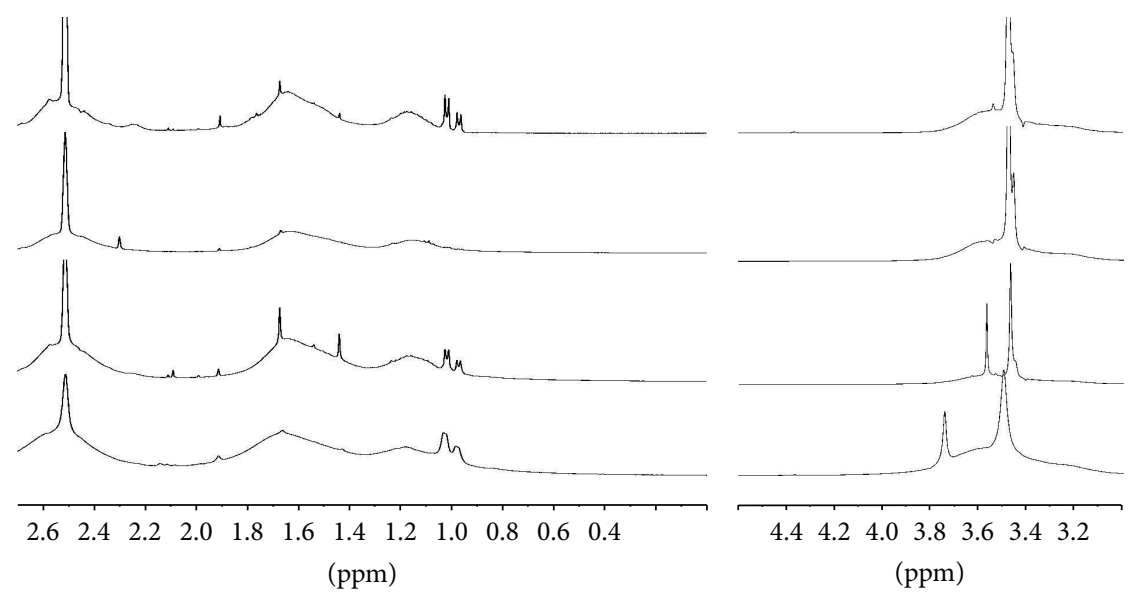

(a)

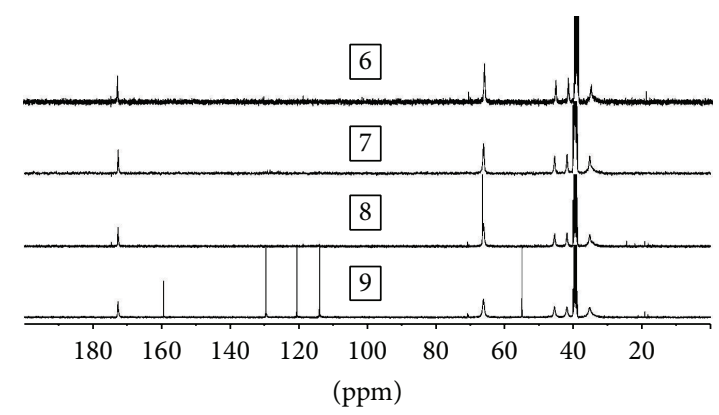

(b)

FIGURE 4: NMR spectra (solvent DMSO) for poly(NAM) synthesized in different solvents: 6 in anisole, 7 in 1,4-dioxane, 8 in toluene, and 9 in THF: (a) ${ }^{1} \mathrm{H}-\mathrm{NMR}$; (b) ${ }^{13} \mathrm{C}-\mathrm{NMR}$.

used in synthesis. Specifically, for this case is the same range for the magnitude order of the molar weight. The dispersion index values are in accordance with the free radical polymerization specific, a high number of the dimensional species. Therefore, the small differences between the two polymer species separated in the case of DPE solvent sustain a growing process at the surface of the separate polymer; process that is kinetic limited by diffusion parameters.

By NMR analyses, the effect of hydrogen bonding interactions on the control of the stereospecificity in radical polymerization can be investigated. It should be noticed that the peak shape and position varied slightly with the tacticity in the NMR spectra. This may be due to the same difference in conformation or to the intra/intermolecular hydrogen bonds in/between polymers with different configuration.
Figures 4(a) and 4(b) show ${ }^{1} \mathrm{H}$ NMR and ${ }^{13} \mathrm{C}$ NMR spectra for poly(NAM). Much simpler, ${ }^{13} \mathrm{C}$ NMR spectra (Figure 4(b)) highlight the specific signals for methylene and methine from the backbone at $35.2 \mathrm{ppm}$, and the methylene bonded on the nitrogen $\left(\mathrm{H}_{2} \mathrm{C}-\mathrm{N}-\mathrm{CH}_{2}\right)$ at $45.4-41.8 \mathrm{ppm}$ and those bonded on the oxygen $\left(\mathrm{H}_{2} \mathrm{C}-\mathrm{O}-\mathrm{CH}_{2}\right)$ at $66.2 \mathrm{ppm}$. All the considered quaternary carbonyl carbons exhibit the same relaxation found at $172.6 \mathrm{ppm}$. When poly(NAM) was synthesized in $\mathrm{D}$, there is a split of the ether carbon (66.4 and $66.2 \mathrm{ppm}$ ) that can be because of the changes in the morpholine ring conformation.

The proton spectra (Figure 4(a)) reveal the hydrogen signals of methylene groups in the backbone at $1-2.2 \mathrm{ppm}$ and for those in morpholine ring at 3.4-3.5 ppm. Because the morpholine ring is relatively bulky and flexible, we were expecting a preferential arrangement of the main chain. 


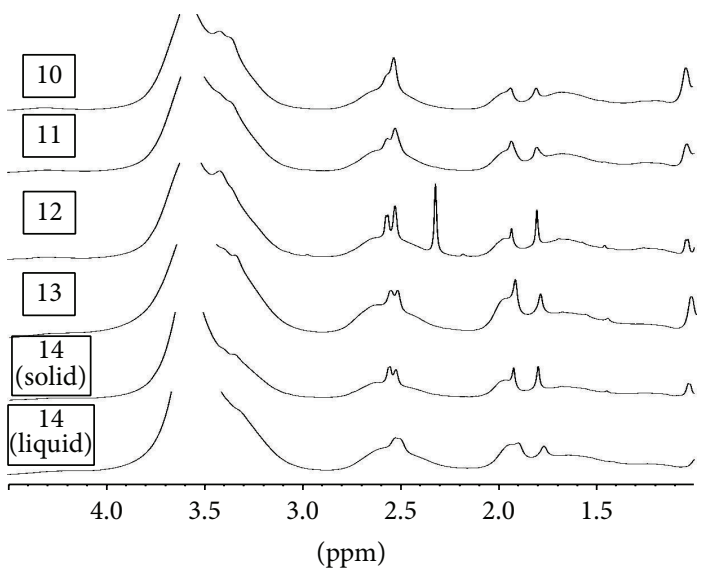

(a)

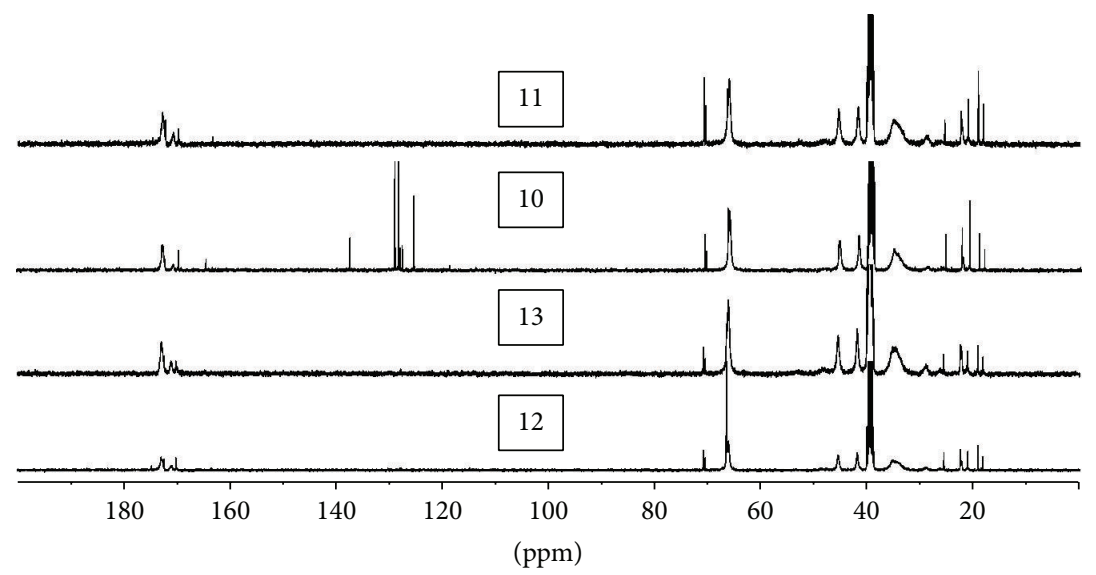

(b)

FIGURE 5: NMR spectra (solvent DMSO) for poly(NMNVA) synthesized in different solvents: 10 in methanol, 11 in 1,4-dioxane, 12 in THF, 13 in toluene, and 14 in diphenyl ether (solid and liquid phase): (a) ${ }^{1} \mathrm{H}-\mathrm{NMR}$; (b) ${ }^{13} \mathrm{C}-\mathrm{NMR}$.

Analyzing the region of the main chain of methylene groups, no remark of splitting or variation of the signals was observed. This can be interpreted as a lack of influence of the solvent on monomer unit conformation. However, increasing the polarity of the solvent the signal for methylene in morpholine ring is splitting, showing the distinct displacements for $\mathrm{H}_{2} \mathrm{C}$ $\mathrm{N}-\mathrm{CH}_{2}(3.45 \mathrm{ppm})$ and $\mathrm{H}_{2} \mathrm{C}-\mathrm{O}-\mathrm{CH}_{2}$ (3.47 ppm).

For NMNVA, we can talk about the potential stereospecific regions corresponding to the two-side chain methyl: $\alpha$ region for the one bonded to the carbonyl group and $\beta$-region for the one bonded to the nitrogen atom (Figure 5(a)).

${ }^{13} \mathrm{C}$ NMR spectra (Figure 5(b)) confirm the elemental analyses results and show the specific signals for $\alpha-\mathrm{CH}_{3}$ at $18-21 \mathrm{ppm} ; \beta-\mathrm{CH}_{3}$ at $22-26 \mathrm{ppm}, \mathrm{CH}_{2}$ from the backbone at $35 \mathrm{ppm}$; $\mathrm{CH}$ from the backbone at 42 and $45 \mathrm{ppm}$ and at $172 \mathrm{C}=\mathrm{O}$. Unfortunately, this is not enough to determine the tacticity dyad.

The complexity of ${ }^{1} \mathrm{H}$ NMR spectra discloses a broadened signal located around $3.5 \mathrm{ppm}$. This peak includes the protons from the backbone $\left(\mathrm{CH}_{2}\right.$ and $\left.\mathrm{CH}\right)$ and two $\mathrm{H}_{3} \mathrm{C}$ distinct regions for $\alpha$ - and $\beta-\mathrm{CH}_{3}: 1.1-2 \mathrm{ppm}$ for $\beta-\mathrm{CH}_{3}$ and 2.5$3 \mathrm{ppm}$ for $\alpha-\mathrm{CH}_{3}$. The specific signal for AIBN methyl appears around $0.9-1 \mathrm{ppm}$. It should be noted that the shape and position of the peaks for $\alpha$ and $\beta$ regions varied slightly depending on the tacticity.

Thereby, for $\beta-\mathrm{CH}_{3}$, we can delimit the specific signal for $\mathrm{rr}$ triade: $1.6 \mathrm{ppm}$ at broadening, $\mathrm{mr}$ at $1.7-1.8 \mathrm{ppm}$, and $\mathrm{mm}$ around $1.9 \mathrm{ppm}$. For both methylene regions, a relative fraction of the isotactic orientation can be observed. At the end of the polarity interval, distinct triads cannot be separated because of the overlapped mr signal (Figure 5(a)). Table 4 summarizes the evolution of stereospecificity for both methylene regions. For both $\alpha$ and $\beta$ regions, an evolution with maximum for THF is observed.

In order to see if they obey the Bernoullian statistics, we tested three samples by using the triad tacticity information. Conditional probability $\mathrm{Pr} / \mathrm{m}$ that a monomer is added to the growing end having a racemo configuration in mesofashion and reverse probability $\mathrm{Pm} / \mathrm{r}$ are given by the following relations:

$$
\begin{aligned}
\mathrm{P}_{\mathrm{rm}} & =\frac{\mathrm{mr}}{(2 \mathrm{rr}+\mathrm{mr})}, \\
\mathrm{P}_{\mathrm{mr}} & =\frac{\mathrm{mr}}{(2 \mathrm{~mm}+\mathrm{mr})} .
\end{aligned}
$$




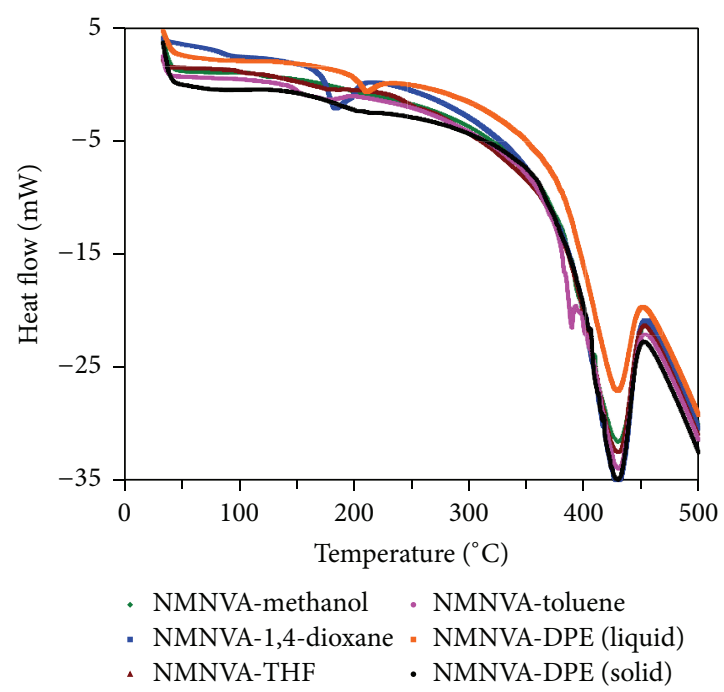

(a)

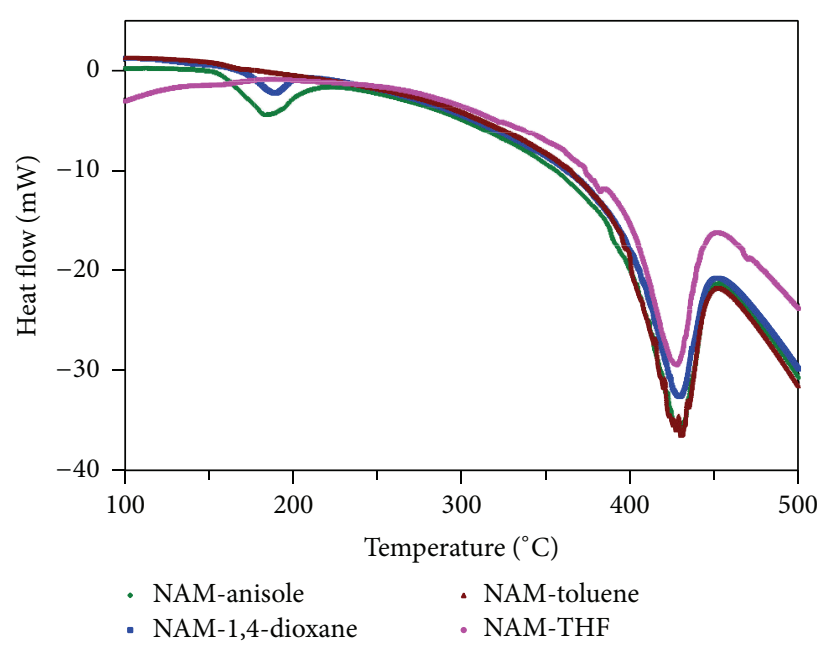

(b)

Figure 6: DSC curves of poly(NMNVA) (a) and poly(NAM) (b) [2nd heating run, heating rate $5^{\circ} \mathrm{C} / \mathrm{min} ; \mathrm{N}_{2}$ flow; $30 \mathrm{~mL} / \mathrm{min}$ ].

If $\mathrm{P}_{\mathrm{rm}}+\mathrm{P}_{\mathrm{mr}}=1$, then chain propagation obeys Bernoullian statistics. The sum for both regions is less than the unity, pointing a non-Bernoullian model. Only for $\beta_{\mathrm{CH} 3}$ in 1,4-dioxane and $\alpha_{\mathrm{CH} 3}$ in THF, the values are closed to unity $(\geq 0.8)$. This points out that, with the increase of the polarity of the reaction medium, the evolution of the process approaches the Bernoullian model. In fact, the different evolutions can be explained by simultaneous different spatial orientation due to the steric hindrance on the account of the molar volume of each sequence.

3.2.2. Thermal Investigations. Thermal analysis of all samples, shown in Figure 6, shows one small peak between $50-210^{\circ} \mathrm{C}$. Taking into account the associate weight loss $(1 \div 20 \%)$, this is more probable due to the water evaporation. Although we might have expected a different thermal comportment related to $\mathrm{rr}$ content, all samples exhibit one broad endothermic peak at $427^{\circ} \mathrm{C}$, similar to poly (N-methyl methacrylamide) with a maximum 51\% rr [20]. It can be concluded that, from low to $50 \%$ tacticity, no changes are recorded from amorphous to crystalline state.

\section{Conclusions}

Radical polymerization of NAM and NMNVA was carried out using different solvents as reaction medium. The nature of solvent, understanding as polarity, affects the polymerization of the proposed monomers kinetically, dimensionally, and structurally. Although the stereochemistry is not so spectacular, it is clear that, using free radical polymerization and the adequate solvent, a structural modification of poly(NMNVA) can be induced. The information obtained in this work is useful in devising stereoregulation methods for radical polymerization of NMNVA.

\section{Competing Interests}

The authors declare that they have no competing interests.

\section{Acknowledgments}

The work of Anca Aldea has been funded by the Sectorial Operational Program Human Resources Development 20072013 of the Ministry of European Funds through the Financial Agreement POSDRU/159/1.5/S/132397.

\section{References}

[1] H. G. Börner, H. Kühnle, and J. Hentschel, "Making 'smart polymers' smarter: modern concepts to regulate functions in polymer science," Journal of Polymer Science, Part A: Polymer Chemistry, vol. 48, no. 1, pp. 1-14, 2010.

[2] H. G. Börner and H. Schlaad, "Bioinspired functional block copolymers," Soft Matter, vol. 3, no. 4, pp. 394-408, 2007.

[3] H.-A. Klok and H. Schlaad, Eds., Peptide Hybrid Polymers, Advances in Polymer Science, Springer, Berlin, Germany, 2006.

[4] J. C. M. Van Hest and D. A. Tirrell, "Protein-based materials, toward a new level of structural control," Chemical Communications, no. 19, pp. 1897-1904, 2001.

[5] H.-A. Klok, "Biological-synthetic hybrid block copolymers: combining the best from two worlds," Journal of Polymer Science, Part A: Polymer Chemistry, vol. 43, no. 1, pp. 1-17, 2005.

[6] Z. Guan, "Supramolecular design in biopolymers and biomimetic polymers for advanced mechanical properties," Polymer International, vol. 56, no. 4, pp. 467-473, 2007.

[7] E. S. Gil and S. M. Hudson, "Stimuli-reponsive polymers and their bioconjugates," Progress in Polymer Science, vol. 29, no. 12, pp. 1173-1222, 2004.

[8] I. Y. Galaev and B. Mattiasson, “'Smart' polymers and what they could do in biotechnology and medicine," Trends in Biotechnology, vol. 17, no. 8, pp. 335-340, 1999. 
[9] W. Jaeger, J. Bohrisch, and A. Laschewsky, "Synthetic polymers with quaternary nitrogen atoms-synthesis and structure of the most used type of cationic polyelectrolytes," Progress in Polymer Science, vol. 35, no. 5, pp. 511-577, 2010.

[10] Z. M. O. Rzaev, S. Dinçer, and E. Pişkin, "Functional copolymers of $\mathrm{N}$-isopropylacrylamide for bioengineering applications," Progress in Polymer Science, vol. 32, no. 5, pp. 534-595, 2007.

[11] F. D’Agosto, M.-T. Charreyre, L. Veron, M.-F. Llauro, and C. Pichot, "Kinetic study of free-radical solution copolymerization of $\mathrm{N}$-acryloylmorpholine with an activated ester-type monomer, N-acryloxysuccinimide," Macromolecular Chemistry and Physics, vol. 202, no. 9, pp. 1689-1699, 2001.

[12] F. D’Agosto, M.-T. Charreyre, F. Mélis, B. Mandrand, and C. Pichot, "High molecular weight hydrophilic functional copolymers by free-radical copolymerization of acrylamide and of $N$ acryloylmorpholine with $N$-acryloxysuccinimide: application to the synthesis of a graft copolymer," Journal of Applied Polymer Science, vol. 88, no. 7, pp. 1808-1816, 2003.

[13] F. D’Agosto, R. Hughes, M.-T. Charreyre, C. Pichot, and R. G. Gilbert, "Molecular weight and functional end group control by RAFT polymerization of a bisubstituted acrylamide derivative," Macromolecules, vol. 36, no. 3, pp. 621-629, 2003.

[14] U. Voigt, V. Khrenov, K. Tauer, M. Hahn, W. Jaeger, and R. von Klitzing, "The effect of polymer charge density and charge distribution on the formation of multilayers," Journal of Physics: Condensed Matter, vol. 15, no. 1, pp. S213-S218, 2003.

[15] D. Fischer, H. Dautzenberg, K. Kunath, and T. Kissel, "Poly(diallyldimethylammonium chlorides) and their $\mathrm{N}$ methyl-N-vinylacetamide copolymer-based DNA-polyplexes: role of molecular weight and charge density in complex formation, stability, and in vitro activity," International Journal of Pharmaceutics, vol. 280, no. 1-2, pp. 253-269, 2004.

[16] T. Hirano, Y. Okumura, M. Seno, and T. Sato, "Remarkable effect of hydrogen-bonding interaction on stereospecificity in the radical polymerization of N-vinylacetamide," European Polymer Journal, vol. 42, no. 9, pp. 2114-2124, 2006.

[17] B. Ray, Y. Okamoto, M. Kamigaito et al., "Effect of tacticity of poly(N-isopropylacrylamide) on the phase separation temperature of its aqueous solutions," Polymer Journal, vol. 37, no. 3, pp. 234-237, 2005.

[18] H. Ajiro and M. Akashi, "Radical polymerization of novel $N$-substituted- $N$-vinylformamide derivatives with bulky chiral substitutents," Journal of Polymer Science, Part A: Polymer Chemistry, vol. 50, no. 1, pp. 134-141, 2012.

[19] T. Nakano, K.-I. Makita, and Y. Okamoto, "Stereochemistry of free-radical polymerization of bulky vinyl esters," Polymer Journal, vol. 30, no. 8, pp. 681-683, 1998.

[20] W. Liu, T. Nakano, and Y. Okamoto, "Stereocontrol in radical polymerization of $\mathrm{N}, \mathrm{N}$-dimethylacrylamide and $\mathrm{N}, \mathrm{N}$ diphenylacrylamide and thermal properties of syndiotactic poly(methyl acrylate)s derived from the obtained polymers," Polymer Journal, vol. 32, no. 9, pp. 771-777, 2000.

[21] J. Zhang, W. Liu, T. Nakano, and Y. Okamoto, "Stereospecific radical polymerization of $N$-methyl methacrylamide," Polymer Journal, vol. 32, no. 8, pp. 694-699, 2000.

[22] Y. Okamoto and E. Yashima, "Asymmetric polymerization of methacrylates," Progress in Polymer Science, vol. 15, no. 2, pp. 263-298, 1990.

[23] Y. Okamoto, "Chiral polymers for resolution of enantiomers," Journal of Polymer Science, Part A: Polymer Chemistry, vol. 47, no. 7, pp. 1731-1739, 2009.
[24] A. Abe and D. R. Bloch, Polymer Handbook, Edited by J. Brandrup, E. H. Immergut, and E. A. Grulke, Wiley-Interscience, 4th edition, 1999.

[25] F. S. Dainton and W. D. Sisley, "Polymerization of methacrylamide in aqueous solution. Part 1.-Hydrogen-peroxide photosensitized reaction," Transactions of the Faraday Society, vol. 59, pp. 1369-1376, 1963.

[26] D. N. Schulz, "Water-soluble polymer synthesis: theory and practice," in Water-Soluble Polymers: Synthesis, Solution Properties, and Applications, vol. 467 of ACS Symposium Series, chapter 3, pp. 57-73, American Chemical Society, 1991.

[27] A. Gallardo and J. San Román, "Kinetic and microstructural parameters of the free-radical copolymerization of 2hydroxyethyl methacrylate with methacrylic monomers bearing bulky polar side-groups," Polymer, vol. 34, no. 3, pp. 567573, 1993.

[28] B. Badey, P. Boullanger, A. Domard, P. Cros, T. Delair, and C. Pichot, "Radically initiated polymerization of a methacryloylamido-terminated saccharide, 1. Monomer synthesis, homopolymerization and characterizations," Macromolecular Chemistry and Physics, vol. 197, no. 11, pp. 3711-3728, 1996.

[29] E. Pretsch, Ph. Buhlmann, and M. Badertscher, Structure Determination of Organic Compounds: Tables of Spectral Data, Springer, Berlin, Germany, 2009, Revised and Enlarged Edition: chapter 4: ${ }^{13} \mathrm{C}$ NMR Spectroscopy, pp. 69-156, chapter $5:{ }^{1} \mathrm{H}$ NMR Spectroscopy, pp. 157-242, chapter 7: IR Spectroscopy, pp. 26-337. 

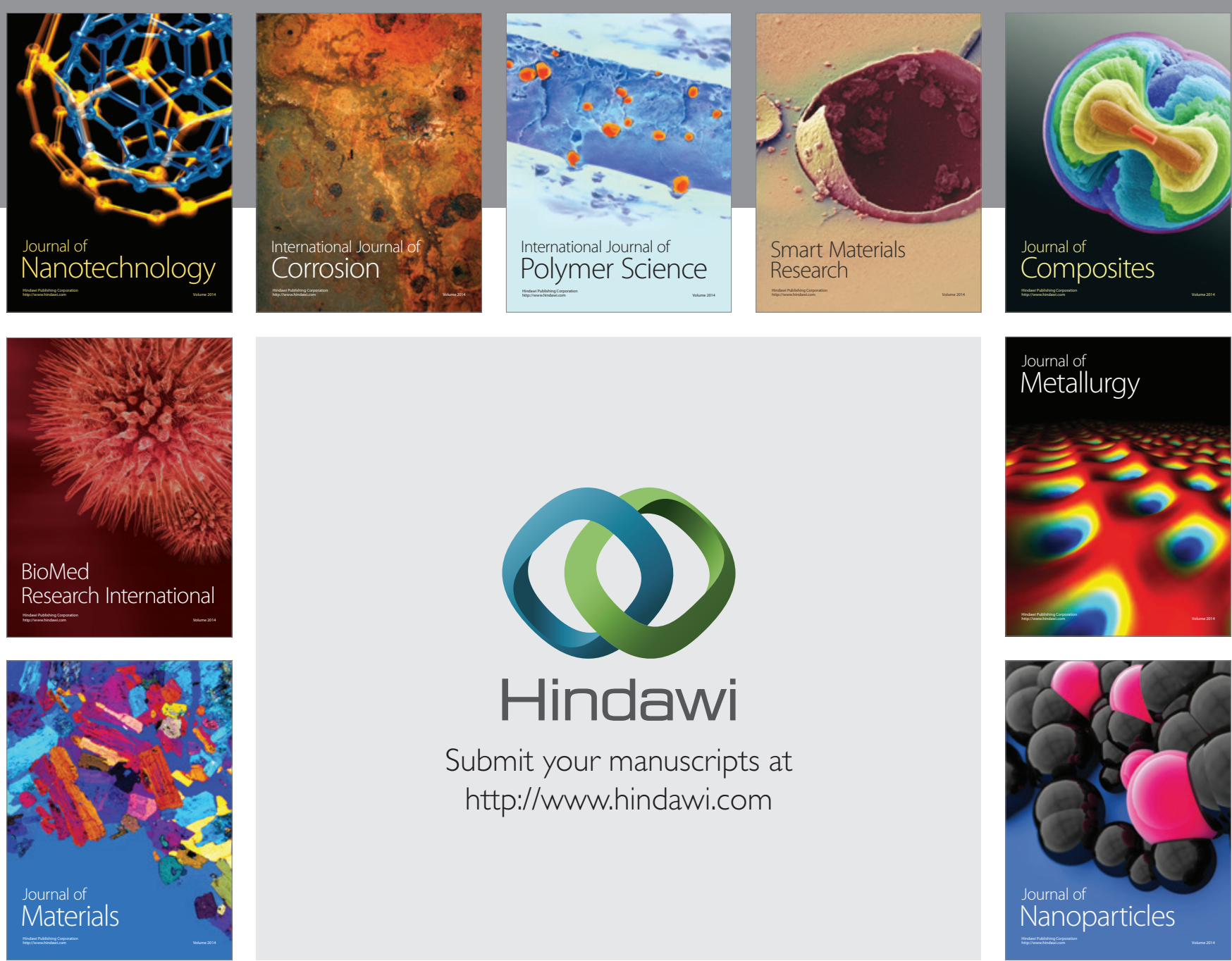

\section{Hindawi}

Submit your manuscripts at

http://www.hindawi.com

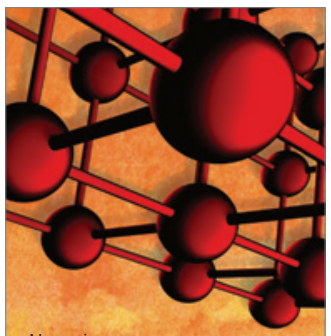

Materials Science and Engineering
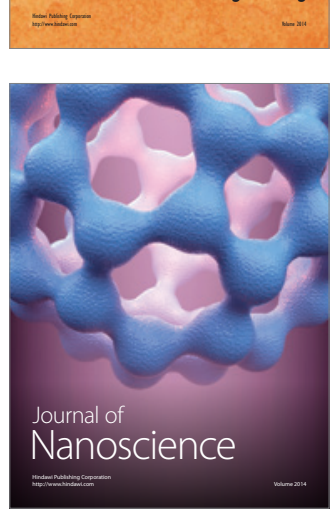
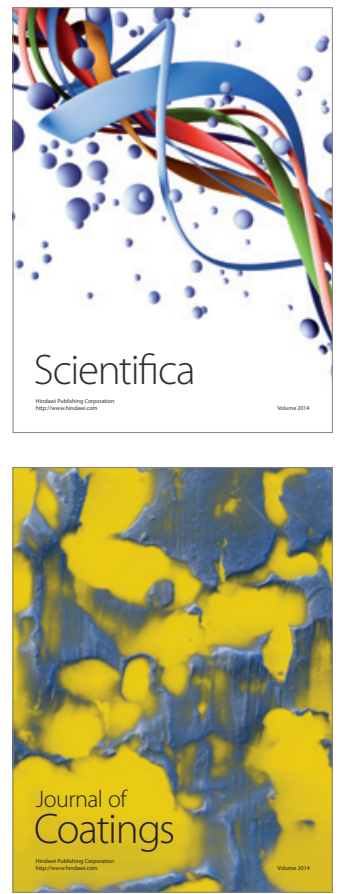
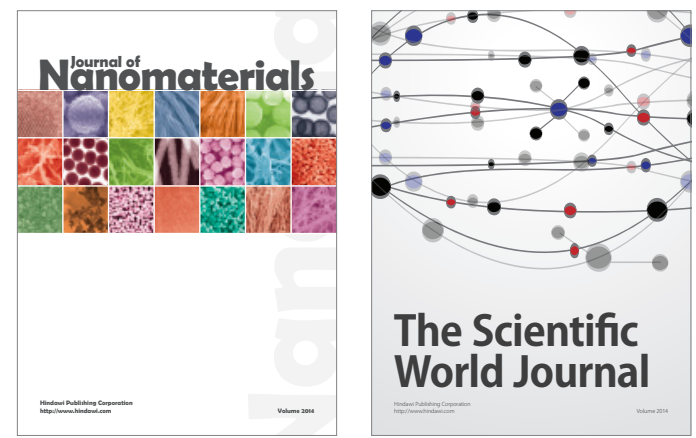

The Scientific World Journal
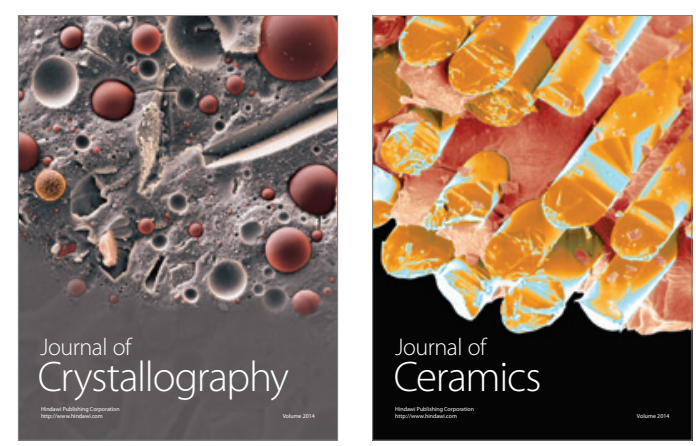
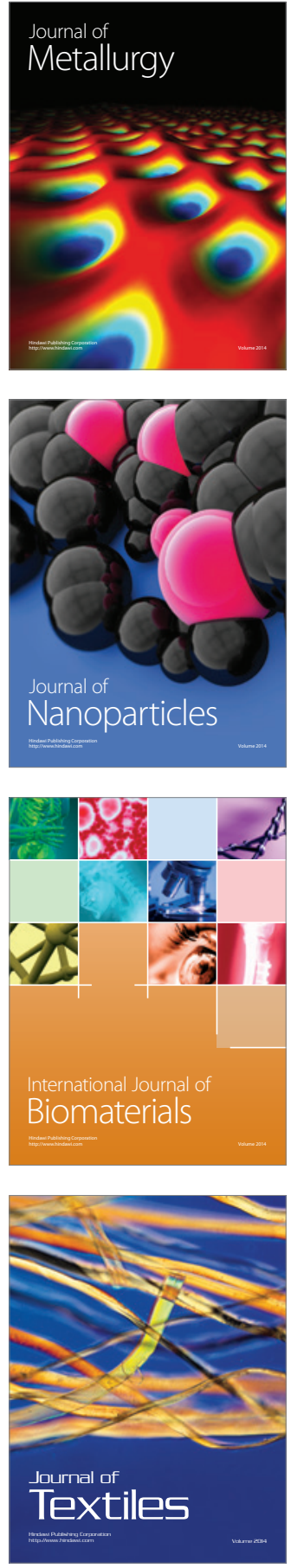